\section{TIME FOR AN 'OCEAN INDEX'}

What is our international investment in oceanography, and how has it changed over the years? Two seemingly simple questions that have daunted our community repeatedly. The first of these two questions is reasonably straightforward. In fact, in the U.S., several organizations (CORE and the National Academy of Sciences come to mind) have made valiant attempts at quantifying this investment. The difficulty comes in designing the cubbyholes into which we want to categorize the investment: are we just counting basic research funds?; do we include the infrastructure of ships and satellites?; how do we include operational costs?; etc. Nevertheless, the question is usually best defined in terms of the problem being addressed. If we want to know how much basic research is being conducted, for example, a survey of government sponsor accounts is usually sufficient.

But it's the second of these two questions that merits some special attention now in the oceanographic community. After all, the trend of investments in oceanography might be a better indicator of the health of our field than the current total investment. The problem, of course, is that ours is such a dynamic field that it's difficult to standardize the 'bean counting'. Because remote sensing programs, for example, undergo financial buildups and occasional years of resource 'spikes' (i.e. large costs for building satellites), including these efforts in a cumulative assessment of trends can severely bias the time series.

The answer is to develop an international index of oceanographic investment. Like the Dow Jones average, and similar such financial indicators, an 'Ocean Index' would be a useful tool for assessing the health and trends of our 'business'. Taking our cue from the financial markets, our index could be a blend of long standing programs (e.g. Sea Grant, the Ocean Drilling Program or MAST), as well as a mix of finite-duration initiatives (e.g. JGOFS). We could include well-understood budget lines, such as the U.S. Navy's basic research (6.1) accounts, or specific lines at the Intergovernmental Oceanographic Commission, as well as relevant corporate indicators (e.g. the published sales figures from established large and small oceanographic firms). Other unique financial factors could be included, such as the membership dues receipts from professional societies, or the total ship operating costs of the UNOLS fleet. Yes, these are very different kinds of measures of health, but they are also all expressable in financial terms. Most importantly, they are all determinable over many decades in the past, and thus lend themselves well to a long-term (e.g. 30-50 year) assessment of our community.

The idea for an 'Ocean Index' is not particularly new. Several groups have discussed this, but nobody has made a real go of it. Now is the time. We need this metric to convince the international 'user community' of the status and trends of the oceanographic community. A measure of our growth must be developed.

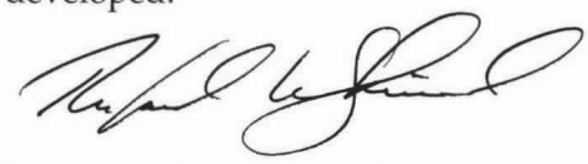

\title{
OCEANOGRAPHY
}

www.tos.org

EDITOR

Richard W. Spinrad

U.S. Naval Observatory

3450 Massachusetts Avenue, NW

Washington, DC 20392-5421 USA

(202) 762-1697 Fax: (202) 762-1025

spinrad.richard@hq.navy.mil

\section{ASSISTANT EDITOR \\ Elizabeth J. Tirpak \\ magazine@tos.org}

\section{ASSOCIATE EDITORS}

Gregg J. Brunskill

Australian Institute of Marine Science PMB No. 3, Townsville, M.C.

Queensland 4810, Australia

(61) 747534481 Fax: (61) 747725852 g.brunskill@aims.gov.au

Ellen R.M. Druffel

Department of Earth System Science

222 Roland Hall University of California Irvine, California 92697-3100 USA

(949) 824-2116 Fax: (949) 824-3256 edruffel@uci.edu

Charles H. Greene

Director, Ocean Resources and Ecosystems Program Department of Earth \& Atmospheric Sciences Cornell University 2130 Snee Hall

Ithaca, New York 14853-2701

(607) 255-5449 Fax: (607) 254-4780 chg2@cornell.edu

James Syvitski

Director, Institute of Arctic and Alpine Research University of Colorado at Boulder 1560 30th Street, Campus Box 450 Boulder, Colorado 80309-4050 USA (303) 492-7909 Fax (303) 492-6388 james.syvitski@colorado.edu

Peter Wadhams Scott Polar Research Institute University of Cambridge Lensfield Road Cambridge CB2 1ER England +44 1223-336542 pw11@phx.cam.ac.uk

\section{DESIGN/PRINTING}

Corporate Press

403 Brightseat Road

Landover, Maryland 20785 USA 